
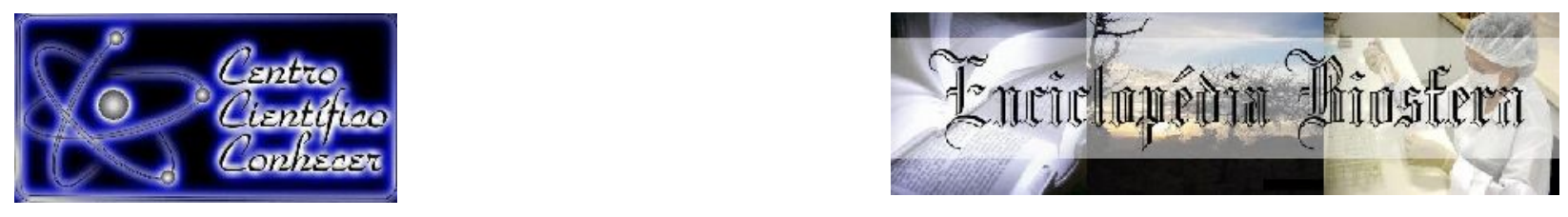

\title{
PERFIL DAS PROPRIEDADES LEITEIRAS DO MUNICÍPIO DE NOVA ERECHIM, SC
}

\author{
Bruna Carla Frozzaํㅜ, Adalgiza Pinto Neto², William de Oliveira ${ }^{3}$, Marcelo Falci Mota², \\ Jonatas Cattelam² \\ ${ }^{1}$ Médica Veterinária Autônoma. Nova Erechim-SC. \\ ${ }^{2}$ Docente. Curso de Medicina Veterinária, Campus Realeza, Universidade Federal da \\ Fronteira Sul, Realeza-PR. \\ ${ }^{3}$ Mestrando. Programa Saúde, Bem-estar Animal e Produção Sustentável na \\ Fronteira Sul, Universidade Federal da Fronteira Sul, Realeza-PR. \\ E-mail: adalgiza.uffs@gmail.com, adalgiza.neto@uffs.edu.br
}

\section{Recebido em: 06/04/2019 - Aprovado em: 10/06/2019 - Publicado em: 30/06/2019 DOI: 10.18677/EnciBio_2019A98}

\begin{abstract}
RESUMO
A região Oeste Catarinense concentra $68 \%$ do rebanho leiteiro do Estado, destacando-se a microrregião de Chapecó, onde se insere o município de Nova Erechim, que representa $23 \%$ do rebanho estadual, caracterizada pela agricultura familiar e alta produtividade de leite. Nesse contexto, objetivou-se analisar o perfil produtivo e reprodutivo das propriedades de Nova Erechim - SC, por meio de questionário semiestruturado a 114 produtores de leite do município, coletando dados relativos a propriedade, animais e ao rebanho leiteiro. Os dados foram tabulados e processados em planilhas eletrônicas, e apresentados sob estatística descritiva. Das 143 propriedades do município, 79,72\% (114/143) participaram deste estudo, onde 92,1\% (105/114) delas possuíam até 30 ha, 94,7\% (108/114) utilizavam mão de obra familiar e 68,4\% (78/114) possuíam rebanhos formados pela Raça Holandesa. A bovinocultura leiteira foi a principal atividade em 68,4\% (78/114) das propriedades e em 31,6\% (36/114) a atividade secundária. 78,95\% (90/114) dos produtores utilizavam inseminação artificial (IA) no rebanho. Além da $I A$, a inseminação artificial em tempo fixo (IATF) e a transferência de embriões em tempo fixo (TETF) foram biotécnicas reprodutivas utilizadas em 33,3\% (38/114) das propriedades. Conclui-se, nas condições desse estudo, que Nova Erechim-SC é caracterizada por pequenas propriedades, tendo a bovinocultura leiteira, com animais das Raças Holandês e Jersey, como atividade primordial de subsistência, onde a IA é difundida em contrapartida as demais biotécnicas reprodutivas. A produção a pasto, associada à suplementação de concentrado e mineral, predomina no município, observando-se a necessidade de controle da qualidade da água utilizada na produção leiteira.
\end{abstract}

PALAVRAS-CHAVE: agricultura familiar, bovino, produção de leite, reprodução animal. 


\title{
PROFILE OF DAIRY FARMS IN NOVA ERECHIM, SANTA CATARINA, BRAZIL
}

\begin{abstract}
The western state of Santa Catarina, Brazil, concentrates $68 \%$ of the dairy cows in the state, with emphasis on the Chapecó microregion, which includes the municipality of Nova Erechim, which presents $23 \%$ of the state's dairy cows. This municipality is characterized by family farming and high milk yield. In this context, the objective of this work was to characterize the productive and reproductive profiles of cows in dairy farms in Nova Erechim. Data about the farm, animals, and dairy herds of 114 milk producers were collected through a semi-structured questionnaire; the municipality had 143 dairy farms. The data were processed in electronic spreadsheets and presented as descriptive statistics. The results showed that $92.1 \%$ (105/114) of the milk producers had areas of up to 30 ha; $94.7 \%(108 / 114)$ used family labor; and $68.4 \%$ (78/114) had dairy herds formed by Holstein cows. Milk production was the main activity in $68.4 \%$ (78/114) of the farms, and a secondary activity in $31.6 \%$ (36/114). Artificial insemination was used by $78.95 \%$ (90/114) of the producers; and fixed-time artificial insemination and fixed-time embryo transfer were reproductive biotechniques used by $33.3 \%(38 / 114)$ of the producers. Thus, according to the results, Nova Erechim is characterized by small farms with dairy cattle of the Holstein and Jersey breeds that present milk production as primary subsistence activity and use of artificial insemination over other reproductive biotechniques. Milk production using animals fed on pastures associated with concentrate and mineral supplementation predominates in the municipality, but a better water quality control is needed for the milk production.
\end{abstract}

KEYWORDS: family farming, cattle, milk production, animal reproduction.

\section{INTRODUÇÃO}

O Brasil possui clima, solo e localização geográfica que permitem a exploração e viabilidade da produção leiteira em todas as épocas do ano. Mezzadri (2016) relatou que a produção leiteira do país vem aumentando gradativamente, com crescimento de 43\%, entre 2005 e 2014. No cenário nacional, Santa Catarina, Paraná e Rio Grande do Sul, juntos, lideraram a produção leiteira. Em 2015, os estados do Sul do Brasil foram responsáveis por $35,2 \%$ da produção brasileira, atingindo também os maiores índices de produtividade, com 2.900 litros/vaca/ano, e crescimento de 3,9\% em relação a 2014 (IBGE, 2016).

Em Santa Catarina, a produtividade média é de 2.755 litros/vaca/ano, sendo a terceira melhor média do país. No ano 2015, a produção de leite em Santa Catarina foi de 3,05 bilhões de litros, sendo observado, na região Oeste do Estado, crescimento de 256\%, entre os anos de 2000 a 2013 (CERON, 2016). A Mesorregião Oeste Catarinense ganhou espaço na produção de leite com auxílio de tecnologias e mão de obra qualificada, tornando-se a principal produtora, respondendo por 74,8\% da produção e 2,23 bilhões de litros (MARCONDES, 2016).

$\mathrm{Na}$ Região Oeste Catarinense encontra-se $68 \%$ do rebanho de vacas do estado, sendo que a microrregião de Chapecó, que engloba o Município de Nova Erechim, representa $23 \%$ do rebanho leiteiro estadual. As pequenas propriedades (até 100 hectares) possuem $91,7 \%$ das vacas ordenhadas na região, deixando clara a importância da agricultura familiar no oeste do Estado (FISCHER et al., 2011). A produção leiteira no município de Nova Erechim é realizada em pequenas propriedades familiares, com cerca de 2.900 cabeças ordenhadas (IBGE, 2016). Ainda segundo dados do IBGE (2016), em 2016 a produção leiteira do município, 
que possui $64,4 \mathrm{~km}^{2}$, foi de 13.230 .000 litros, totalizando 205.434 litros de leite por km²/ano, e produção média de 4.562 litros por vaca/ano, acima das médias brasileira e catarinense.

Várias pesquisas voltadas à qualidade do leite estão sendo desenvolvidas constantemente, como reflexo das exigências e normatizações estabelecidas. No entanto, particularidades regionais e locais, produtivas e reprodutivas dos rebanhos carecem de maiores informações, uma vez que o conhecimento da realidade da produção local é o primeiro passo para adequações e melhorias no sistema de produção (SANTOS JÚNIOR et al., 2016). Por isso dá-se a importância da realização da análise do perfil, tanto produtivo quanto reprodutivo, de um rebanho local. Desse modo, objetivou-se com este estudo analisar o perfil das propriedades leiteiras do município de Nova Erechim, estado de Santa Catarina.

\section{MATERIAL E MÉTODOS}

O município de Nova Erechim - SC, situa-se na Mesorregião de Chapecó, Região Oeste do Estado, a 471 metros de altitude, $26^{\circ} 54^{\prime} 18^{\prime \prime}$ Latitude Sul e $52^{\circ} 54^{\prime}$ 14" Longitude Oeste, com área de $64,4 \mathrm{~km}^{2}$ e 4.275 habitantes (CIDADE-BRASIL, 2016). Segundo a Secretaria da Agricultura do Município, Nova Erechim possui 143 propriedades leiteiras, que foram visitadas, no período de setembro a outubro de 2017, sendo que 114 delas se dispuseram a participar deste estudo, aprovado pelo Comitê de Ética em Pesquisa da Universidade Federal da Fronteira Sul (Certificado 68754317.2.0000.5564).

Foi realizada aplicação de questionário semiestruturado ao produtor, durante cada visita, baseando-se naquele elaborado por Santos Júnior et al. (2016). Coletaram-se dados relativos à(o/s):

- Propriedade: tipo da mão de obra, atividade primária e secundária, tamanho, localização e participação em cooperativas/ associações;

. Características do rebanho/animais: número de animais, número fêmeas lactantes, raça(s), produção de leite diária e mensal, pesagem do leite, sala de ordenha e controle de mastite;

- Manejo nutricional: dados das pastagens, da suplementação volumosa, do concentrado e sal mineral;

- Manejo reprodutivo: uso de inseminação artificial (IA), origem do sêmen, uso de sêmen sexado, de acasalamento programado e de outras biotécnicas reprodutivas, vantagens e dificuldades da IA, presença do inseminador e botijão de sêmen, uso de rufião, uso de monta natural (MN) e presença do touro, origem e raça do touro, permanência do touro junto às fêmeas, manejo diferencial do touro, realização de exames andrológicos, vantagens da MN, anotações zootécnicas e de coberturas, utilização de outras biotécnicas reprodutivas;

Características da água utilizada para o manejo de ordenha e animais do rebanho: procedência, realização de análises e tratamento.

Os dados obtidos foram tabulados e organizados por tamanho da propriedade (até 10 ha; 10,1 a 20 ha; 20,1a 30 ha e maior que 30 ha), apresentados sob a forma descritiva, sendo a frequência de ocorrência em porcentagem, e os dados de produção em média \pm desvio padrão, calculados utilizando-se o Microsoft Excel. 


\section{RESULTADOS E DISCUSSÃO}

Das propriedades leiteiras do município de Nova Erechim, 79,72\% (114/143) foram inseridas neste estudo, e agrupadas de acordo com a extensão territorial, sendo que $24,6 \%(28 / 114)$ possuíam até 10 ha, 43,8\% (50/114) de 10,1 a 20 ha, $23,7 \%(27 / 114)$ de 20,1 a 30 ha e $7,9 \%(9 / 114)$ acima de 30 ha (Tabela 1). Os resultados observados demonstram que a maior parte das propriedades leiteiras do município possui pequena extensão territorial, cenário característico da Região Oeste catarinense, sendo que 92,1\% apresentam até 30 ha. Santos Junior et al. (2016) relataram que das 255 propriedades leiteiras do Sudoeste paranaense, $27,8 \%(71 / 255)$ delas possuíam até 10 ha, 31,76\% (81/255) entre 10 a 20 ha, $23,92 \%(61 / 255)$ entre 20 a 30 ha e $16,5 \%(42 / 255)$ acima de 30 ha. Zanin et al. (2014) estudaram 210 propriedades de três municípios do Oeste Catarinense, e observaram que $39 \%(81 / 210)$ das propriedades possuíam área de 10,1 a 20 ha, enquanto propriedades de 1,0 a 10 ha e de 20,1 a 30 hectares representaram $21 \%$ $(45 / 210)$ cada. Apenas $19 \%$ (40/210) das propriedades possuíam tamanho superior a 30,1 ha.

Observou-se neste estudo, que a distribuição das propriedades até 30 ha foi semelhante ao descrito por Zanin et al. (2014) e por Santos Junior et al. (2016). No entanto, a proporção de propriedades maiores que 30 ha foi menor quando comparada ao descrito pelos autores acima citados.

Dos 4973 bovinos das propriedades estudadas (43,6 $\pm 32,9$ animais/propriedade), $42,61 \%$ (2119/4973) eram fêmeas em lactação $(20,3 \pm 14,8$ fêmeas lactantes/propriedade) com produção total de 1.183 .335 litros $/ \mathrm{mês}$, o que representa produção média por propriedade de 346,1 \pm 369,9 litros/dia $(15,3 \pm 7,2$ litros/animal/dia) (Tabela 1). A alta produtividade observada neste estudo pode estar atrelada a utilização de animais de raças especializadas pelos produtores de Nova Erechim, associada ao adequado manejo nutricional, uma vez que animais da Raça Holandesa foram utilizados em $68,4 \%(78 / 114)$ das propriedades, seguida pela raça Jersey $25,4 \%$ (29/114), (Tabela 1).

TABELA 1. Perfil zootécnico das propriedades leiteiras do município de Nova Erechim, Estado de Santa Catarina.

\begin{tabular}{|c|c|c|c|c|c|}
\hline \multirow[t]{2}{*}{ Parâmetros avaliados } & \multicolumn{5}{|c|}{ Tamanho da Propriedade (Hectares) } \\
\hline & Até 10 & $10,1-20$ & $20,1-30$ & $\begin{array}{c}\text { Maior que } \\
30\end{array}$ & Média \\
\hline Número bovinos & $29,0+18,2$ & $40,5+22,5$ & $52,6+31,5$ & $79,4+72,2$ & $43,6+32,9$ \\
\hline Fêmeas lactação & $14,8+10,9$ & $18,9 \pm 10,8$ & $22,7 \pm 11,3$ & $40,8+33,2$ & $20,3 \pm 14,8$ \\
\hline Produção diária leite & $\begin{array}{c}190,5 \pm \\
180,0\end{array}$ & $\begin{array}{c}343,4 \pm \\
300,1\end{array}$ & $\begin{array}{c}380,3 \pm \\
289,0\end{array}$ & $\begin{array}{l}732,0 \pm \\
864,5\end{array}$ & $\begin{array}{c}346,1 \pm \\
369,9\end{array}$ \\
\hline $\begin{array}{l}\text { Produção diária } \\
\text { leite/animal }\end{array}$ & $13,2 \pm 6,6$ & $16,2 \pm 8,5$ & $15,2 \pm 5,0$ & $17,2 \pm 6,3$ & $15,3 \pm 7,2$ \\
\hline $\begin{array}{l}\text { Animais da Raça } \\
\text { Holandês (\%) }\end{array}$ & $\begin{array}{c}50,0 \\
(14 / 28)\end{array}$ & $\begin{array}{c}74,0 \\
(37 / 50)\end{array}$ & $\begin{array}{c}74,1 \\
(20 / 27)\end{array}$ & $\begin{array}{l}77,8 \\
(7 / 9)\end{array}$ & $\begin{array}{c}68,4 \\
(78 / 114)\end{array}$ \\
\hline $\begin{array}{l}\text { Animais da Raça Jersey } \\
(\%)\end{array}$ & $\begin{array}{c}39,3 \\
(11 / 28)\end{array}$ & $\begin{array}{c}22,0 \\
(11 / 50)\end{array}$ & $\begin{array}{c}18,5 \\
(5 / 27)\end{array}$ & $\begin{array}{l}22,2 \\
(2 / 9)\end{array}$ & $\begin{array}{c}25,4 \\
(29 / 114)\end{array}$ \\
\hline $\begin{array}{l}\text { Animais de Raças } \\
\text { Mestiças (\%) }\end{array}$ & $\begin{array}{c}10,7 \\
(3 / 28)\end{array}$ & $\begin{array}{c}4,0 \\
(2 / 50)\end{array}$ & $\begin{array}{c}7,4 \\
(2 / 27)\end{array}$ & $\begin{array}{c}0,0 \\
(0 / 9)\end{array}$ & $\begin{array}{c}6,1 \\
(7 / 114)\end{array}$ \\
\hline Anotação Zootécnica (\%) & $\begin{array}{c}89,3 \\
(25 / 28)\end{array}$ & $\begin{array}{c}92,0 \\
(46 / 50)\end{array}$ & $\begin{array}{c}85,2 \\
(23 / 27)\end{array}$ & $\begin{array}{l}77,8 \\
(7 / 9)\end{array}$ & $\begin{array}{c}88,6 \\
(101 / 114)\end{array}$ \\
\hline
\end{tabular}

Casari e Tormem (2011) avaliaram 507 animais de 10 propriedades localizadas no município de Chapecó - SC, e relataram que a frequência de vacas ordenhadas foi de 32,9\% (167/507) vacas/dia, com produção de 2.120 litros, o que 
corresponde a 12,7 litros/vaca/dia. Nova Erechim pertence à microrregião de Chapecó, e esses dados demonstram que apesar das cidades serem próximas, e semelhantes quanto à disponibilidade de tecnologias, tipo de relevo e clima, a produção de leite média/dia observada no Município de Nova Erechim (Tabela 1) é superior a relatada por Casari e Tormem (2011).

Santos Junior et al. (2016) relataram média 31,05 $\pm 20,81$ animais no rebanho das propriedades leiteiras de Realeza-PR, sendo 12,34 \pm 9,54 fêmeas em lactação, com produção média diária de 135,13 \pm 161,41 litros de leite/propriedade e produção média/animal/dia de 9,51 \pm 4,39 litros de leite. Os resultados apresentados na Tabela 1, oriundos do Município de Nova Erechim são superiores aos relatados por Santos Junior et al. (2016) para o Sudoeste do Paraná.

Em estudo desenvolvido em 50 propriedades leiteiras de oito municípios da região Sul do Estado de Santa Catarina, Werncke et al. (2016) relataram que em propriedades familiares com ênfase na atividade leiteira, a produção diária média foi de 258,2 $\pm 237,6$ litros, o que representa 10,44 \pm 4,96 litros de leite/vaca/dia. Embora a produção diária de leite relatada por Werncke et al. (2016) seja superior a encontrada neste estudo (Tabela 1), a produção média/animal/dia foi inferior a encontrada em Nova Erechim.

Neves (2014) ao coletar os dados de 1653 propriedades rurais em 293 municípios de Santa Catarina, relatou que $76,5 \%$ dos rebanhos eram compostos por animais de raça Holandesa, semelhante ao encontrado neste estudo (Tabela 1). Werncke et al. (2016) relataram predomínio da Raça Jersey, presente em quase todas as propriedades de seu estudo, desenvolvido no sul de Santa Catarina. Winck e Thaler Neto (2012) relataram que no Alto Vale do Itajaí, 58,2\% das propriedades utilizavam a Raça Jersey, enquanto na região do meio oeste, em 58,3\% predominava a raça Holandesa, principalmente em rebanhos maiores, enquanto animais sem raça definida estavam presentes somente em pequenas propriedades. Esses dados contrastam ao encontrado em Nova Erechim, no qual $68 \%$ dos animais eram da Raça Holandesa, 25\% Raça Jersey e 6,1\% de animais mestiços (Tabela 1).

Os atuais sistemas de produção submetem os animais a condições estressantes que tendem a afetar negativamente a eficiência reprodutiva dos animais e, por consequência, a produtividade e a lucratividade do rebanho, tornando-se necessário o controle zootécnico mais rigoroso. Nesse quesito, o controle reprodutivo, estabelecido pela anotação zootécnica auxilia na identificação de problemas e possibilita soluções (BERGAMASCHI et al., 2010). Observou-se que nas propriedades de Nova Erechim, o controle zootécnico foi realizado em $88,6 \%$ das propriedades (Tabela 1), o que possivelmente contribui para o potencial produtivo do município.

A bovinocultura leiteira foi a principal atividade realizada em $68,4 \%(78 / 114)$ das propriedades estudadas, como mostra a Tabela 2. Santos Junior et al. (2016) observaram que 67,84\% (173/255) das propriedades de Realeza - PR, no Sudoeste do Paraná, consideravam a produção de leite como principal atividade desenvolvida, semelhante ao observado em Nova Erechim. 
TABELA 2. Atividades desenvolvidas e tipo de mão de obra utilizada nas propriedades leiteiras do município de Nova Erechim, Estado de Santa Catarina.

\begin{tabular}{|c|c|c|c|c|c|c|}
\hline \multirow{2}{*}{\multicolumn{2}{|c|}{ Parâmetros avaliados }} & \multicolumn{5}{|c|}{ Tamanho da Propriedade (Hectares) } \\
\hline & & Até 10 & $10,1-20$ & $20,1-30$ & $\begin{array}{l}\text { Maior } \\
\text { que } 30\end{array}$ & Média \\
\hline \multirow[t]{4}{*}{$\begin{array}{l}\text { Atividade } \\
\text { Primária }\end{array}$} & $\begin{array}{l}\text { Gado Leiteiro } \\
(\%)\end{array}$ & $\begin{array}{c}71,4 \\
(20 / 28)\end{array}$ & $\begin{array}{c}70,0 \\
(35 / 50)\end{array}$ & $\begin{array}{c}66,7 \\
(18 / 27)\end{array}$ & $\begin{array}{l}55,6 \\
(5 / 9)\end{array}$ & $\begin{array}{c}68,4 \\
(78 / 114)\end{array}$ \\
\hline & Avicultura (\%) & $\begin{array}{c}17,9 \\
(5 / 28)\end{array}$ & $\begin{array}{c}12,0 \\
(6 / 50)\end{array}$ & $\begin{array}{c}11,1 \\
(3 / 27)\end{array}$ & $\begin{array}{l}11,1 \\
(1 / 9)\end{array}$ & $\begin{array}{c}13,2 \\
(15 / 114)\end{array}$ \\
\hline & Suinocultura (\%) & $\begin{array}{c}7,1 \\
(2 / 28)\end{array}$ & $\begin{array}{c}18,0 \\
(9 / 50)\end{array}$ & $\begin{array}{c}14,8 \\
(4 / 27)\end{array}$ & $\begin{array}{c}11,1( \\
1 / 9)\end{array}$ & $\begin{array}{c}14,0 \\
(16 / 114)\end{array}$ \\
\hline & Outra (\%) & $3,6(1 / 28)$ & $0,0(0 / 50)$ & $7,4(2 / 27)$ & $22,2(2 / 9)$ & $4,4(5 / 114)$ \\
\hline \multirow[t]{5}{*}{$\begin{array}{l}\text { Atividade } \\
\text { Secundária }\end{array}$} & $\begin{array}{l}\text { Gado Leiteiro } \\
(\%)\end{array}$ & $\begin{array}{c}28,6 \\
(8 / 28)\end{array}$ & $\begin{array}{c}30,0 \\
(15 / 50)\end{array}$ & $\begin{array}{c}33,3 \\
(9 / 27)\end{array}$ & $\begin{array}{l}44,4 \\
(4 / 9)\end{array}$ & $\begin{array}{c}31,6 \\
(36 / 114)\end{array}$ \\
\hline & Gado Corte (\%) & $0,0(0 / 28)$ & $2,0(1 / 50)$ & $0,0(0 / 27)$ & $11,1(1 / 9)$ & $1,7(2 / 114)$ \\
\hline & Avicultura (\%) & $\begin{array}{c}14,3 \\
(4 / 28)\end{array}$ & $\begin{array}{c}24,0 \\
(12 / 50)\end{array}$ & $\begin{array}{c}33,3 \\
(9 / 27)\end{array}$ & $\begin{array}{l}22,2 \\
(2 / 9)\end{array}$ & $\begin{array}{c}23,7 \\
(27 / 114)\end{array}$ \\
\hline & Suinocultura (\%) & $\begin{array}{c}17,9 \\
(5 / 28)\end{array}$ & $\begin{array}{c}24,0 \\
(12 / 50)\end{array}$ & $\begin{array}{c}22,2 \\
(6 / 27)\end{array}$ & $\begin{array}{l}33,3 \\
(3 / 9)\end{array}$ & $\begin{array}{c}22,8 \\
(26 / 144)\end{array}$ \\
\hline & Outra (\%) & $\begin{array}{c}17,9 \\
(5 / 28)\end{array}$ & $\begin{array}{c}18,0 \\
(9 / 50)\end{array}$ & $\begin{array}{c}37,0 \\
(10 / 27)\end{array}$ & $\begin{array}{l}33,3 \\
(3 / 9)\end{array}$ & $\begin{array}{c}23,7 \\
(27 / 114)\end{array}$ \\
\hline \multirow[t]{2}{*}{$\begin{array}{l}\text { Tipo de Mão } \\
\text { de Obra }\end{array}$} & Familiar (\%) & $\begin{array}{c}96,4 \\
(27 / 28)\end{array}$ & $\begin{array}{c}98,0 \\
(49 / 50)\end{array}$ & $\begin{array}{c}92,6 \\
(25 / 27)\end{array}$ & $\begin{array}{l}77,8 \\
(7 / 9)\end{array}$ & $\begin{array}{c}94,7 \\
(108 / 114)\end{array}$ \\
\hline & Terceirizada (\%) & $3,6(1 / 28)$ & $2,0(1 / 50)$ & $7,4(2 / 27)$ & $22,2(2 / 9)$ & $5,3(6 / 144)$ \\
\hline
\end{tabular}

As atividades secundárias realizadas nas propriedades estudadas foram bovinocultura leiteira e de corte, avicultura, suinocultura, desenvolvidas por $31,6 \%$ (36/114), 23,7\% (27/114) e 22,8\% (26/144) das propriedades, respectivamente. Santos Junior et al. (2016) observaram como atividade secundária em Realeza-PR, a produção leiteira, em $31,76 \%(81 / 255)$ das propriedades estudadas, seguida pela produção de grãos $(24,31 \%$ - 62/255), suinocultura $(0,78 \%$ - 2/255) e avicultura $(0,39 \%$ - 1/255). Winck e Thaler Neto (2012) relataram que em $49,4 \%$ das propriedades estudadas na região do meio oeste de SC, a produção leiteira foi a principal atividade econômica, e em $38,6 \%$ dessas, como segunda atividade, seguida pela suinocultura $(19,0 \%)$ e avicultura $(14,3 \%)$. Zanin et al. (2014) destacaram como as principais atividades geradoras de renda, em municípios de SC, a bovinocultura de leite $(75,71 \%)$ e a suinocultura $(44,76 \%)$.

A diversificação das atividades propicia maior segurança às pequenas propriedades familiares, com agregação de valor e propiciando alternativas para a obtenção de renda (FERNANDES et al., 2018). A pluriatividade é forma de aumentar a renda, com maior autonomia às famílias, redução da vulnerabilidade das atividades agrícolas, fortalecimento das atividades e menor êxodo rural. Por isso é importante a realização de incentivos para a implementação de atividades, através de cursos, assistência técnica e políticas públicas, para que as famílias tenham independência financeira através da pluriatividade (MAKISHI et al., 2016). Nesse contexto, observou-se que em Nova Erechim, 21,9\% (25/114) das propriedades estudadas realizam mais que duas atividades simultaneamente.

Observa-se ainda que 94,7\% (108/114) das propriedades de Nova Erechim utilizam exclusivamente mão de obra familiar, corroborando com Santos Junior et al. (2016) e Winck e Thaler Neto (2012), que relataram predomínio de $96 \%$ e $86,1 \%$ de mão de obra familiar, em municípios do Paraná e Santa Catarina, respectivamente. O maior percentual de mão de obra terceirizada foi observado em propriedades acima de 30 ha (Tabela 2). Esse fato deve estar relacionado a maior extensão 
territorial dessas propriedades, as quais requerem maior necessidade de mão de obra para a realização das atividades diárias, fazendo com que os proprietários contratem terceiros, a afim de cumprir essa demanda.

O modelo de ordenha de balde ao pé foi utilizado em $52 \%(63 / 114)$ das propriedades estudadas, seguido por $41,4 \%$ (46/114) que utilizam ordenha tipo fosso canalizado, e 6,6\% (5/114) que utilizam outros modelos de ordenha (variações dos modelos acima ou robotizada), como mostra a Tabela 3. Esse resultado é semelhante ao observado por Werncke et al. (2016), os quais relataram que 47\% das propriedades estudadas no sul de SC utilizaram ordenha mecânica com balde ao pé, e $51 \%$ da ordenha canalizada ou com transferidor de leite.

TABELA 3. Tipo de ordenha e dados de qualidade do leite observados nas propriedades leiteiras do município de Nova Erechim, Estado de Santa Catarina.

\begin{tabular}{|c|c|c|c|c|c|c|}
\hline \multirow{2}{*}{\multicolumn{2}{|c|}{ Parâmetros avaliados }} & \multicolumn{5}{|c|}{ Tamanho da Propriedade (Hectares) } \\
\hline & & Até 10 & $10,1-20$ & $20,1-30$ & $\begin{array}{l}\text { Maior } \\
\text { que } 30\end{array}$ & Total \\
\hline \multirow{3}{*}{$\begin{array}{l}\text { Tipo de } \\
\text { Ordenha }\end{array}$} & Balde ao Pé (\%) & $\begin{array}{c}71,4 \\
(21 / 28)\end{array}$ & $\begin{array}{c}48,0 \\
(24 / 50)\end{array}$ & $\begin{array}{c}55,6 \\
(14 / 27)\end{array}$ & $\begin{array}{l}44,4 \\
(4 / 9)\end{array}$ & $\begin{array}{c}52,0 \\
(63 / 114)\end{array}$ \\
\hline & Fosso/Canalizada (\%) & $\begin{array}{c}25,0 \\
(7 / 28)\end{array}$ & $\begin{array}{c}44,0 \\
(22 / 50)\end{array}$ & $\begin{array}{c}48,1 \\
(13 / 27)\end{array}$ & $\begin{array}{l}44,4 \\
(4 / 9)\end{array}$ & $\begin{array}{c}41,4 \\
(46 / 114)\end{array}$ \\
\hline & Outro (\%) & $\begin{array}{c}0,0 \\
(0 / 28)\end{array}$ & $\begin{array}{c}8,0 \\
(4 / 50)\end{array}$ & $\begin{array}{c}0,0 \\
(0 / 27)\end{array}$ & $\begin{array}{l}11,1 \\
(1 / 9)\end{array}$ & $\begin{array}{c}6,6 \\
(5 / 114)\end{array}$ \\
\hline \multicolumn{2}{|c|}{ Controle Mastite (\%) } & $\begin{array}{c}100,0 \\
(28 / 28)\end{array}$ & $\begin{array}{c}98,0 \\
(49 / 50)\end{array}$ & $\begin{array}{c}100,0 \\
(27 / 27)\end{array}$ & $\begin{array}{l}100,0 \\
(9 / 9)\end{array}$ & $\begin{array}{c}99,1 \\
(113 / 114)\end{array}$ \\
\hline \multicolumn{2}{|c|}{ Realização CMT (\%) } & $\begin{array}{c}64,3 \\
(18 / 28)\end{array}$ & $\begin{array}{c}86,0 \\
(43 / 50)\end{array}$ & $\begin{array}{c}74,1 \\
(20 / 27)\end{array}$ & $\begin{array}{l}44,4 \\
(4 / 9)\end{array}$ & $\begin{array}{c}74,6 \\
(85 / 114)\end{array}$ \\
\hline \multicolumn{2}{|c|}{ Realização de CCS e CBT } & $\begin{array}{c}96,4 \\
(27 / 28)\end{array}$ & $\begin{array}{c}100,0 \\
(50 / 50)\end{array}$ & $\begin{array}{c}96,3 \\
(26 / 27)\end{array}$ & $\begin{array}{l}100,0 \\
(9 / 9)\end{array}$ & $\begin{array}{c}98,3 \\
(112 / 114)\end{array}$ \\
\hline \multicolumn{2}{|c|}{ Uso de Caneca de Fundo escuro (\%) } & $\begin{array}{c}34,5 \\
(10 / 28)\end{array}$ & $\begin{array}{c}46,0 \\
(23 / 50)\end{array}$ & $\begin{array}{c}25,9 \\
(7 / 27)\end{array}$ & $\begin{array}{l}44,4 \\
(4 / 9)\end{array}$ & $\begin{array}{c}38,6 \\
(44 / 114)\end{array}$ \\
\hline \multicolumn{2}{|c|}{ Realização pré dipping* $\left.{ }^{\star} \%\right)$} & $\begin{array}{c}39,3 \\
(11 / 28)\end{array}$ & $\begin{array}{c}60,0 \\
(30 / 50)\end{array}$ & $\begin{array}{c}59,3 \\
(16 / 27)\end{array}$ & $\begin{array}{l}55,6 \\
(5 / 9)\end{array}$ & $\begin{array}{c}54,4 \\
(62 / 114)\end{array}$ \\
\hline \multicolumn{2}{|c|}{ Realização pós dipping* $(\%)$} & $\begin{array}{c}78,6 \\
(22 / 28)\end{array}$ & $\begin{array}{c}98,0 \\
(49 / 50)\end{array}$ & $\begin{array}{c}88,9 \\
(24 / 27)\end{array}$ & $\begin{array}{l}88,9 \\
(8 / 9)\end{array}$ & $\begin{array}{c}90,4 \\
(103 / 114)\end{array}$ \\
\hline \multicolumn{2}{|c|}{ Manejo de vacas secas (\%) } & $\begin{array}{c}89,3 \\
(25 / 28)\end{array}$ & $\begin{array}{c}86,0 \\
(43 / 50)\end{array}$ & $\begin{array}{c}88,9 \\
(21 / 27)\end{array}$ & $\begin{array}{l}66,7 \\
(6 / 9)\end{array}$ & $\begin{array}{c}86,0 \\
(98 / 114)\end{array}$ \\
\hline \multicolumn{2}{|c|}{ Pesagem do leite (\%) } & $\begin{array}{c}28,6 \\
(8 / 28)\end{array}$ & $\begin{array}{c}50,0 \\
(25 / 50)\end{array}$ & $\begin{array}{c}40,7 \\
(11 / 27)\end{array}$ & $\begin{array}{l}44,4 \\
(4 / 9)\end{array}$ & $\begin{array}{c}42,1 \\
(48 / 114)\end{array}$ \\
\hline \multicolumn{2}{|c|}{ Recebimento leite por qualidade (\%) } & $\begin{array}{c}100,0 \\
(28 / 28)\end{array}$ & $\begin{array}{c}98,0 \\
(49 / 50)\end{array}$ & $\begin{array}{c}100,0 \\
(27 / 27)\end{array}$ & $\begin{array}{l}100,0 \\
(9 / 9)\end{array}$ & $\begin{array}{c}99,1 \\
(113 / 114)\end{array}$ \\
\hline \multicolumn{2}{|c|}{$\begin{array}{l}\text { Participa de Cooperativa/Associação } \\
(\%)\end{array}$} & $\begin{array}{l}21,4 \\
(6 / 28)\end{array}$ & $\begin{array}{c}34,0 \\
(17 / 50)\end{array}$ & $\begin{array}{l}25,9 \\
(7 / 27)\end{array}$ & $\begin{array}{l}44,4 \\
(4 / 9)\end{array}$ & $\begin{array}{c}28,9 \\
(33 / 114)\end{array}$ \\
\hline
\end{tabular}

${ }^{*}$ Dipping é a imersão dos tetos em uma solução antisséptica iodada

Winck e Thaler Neto (2012) observaram que 33,7\% das propriedades realizaram ordenha manual, dessas $96,4 \%$ ordenha mecânica com sistema de balde ao pé e $3,6 \%$ sistema canalizado. Neste estudo, nenhuma propriedade de Nova Erechim utilizou ordenha manual. Manske et al. (2017) observaram que 66,7\% (30 propriedades) dispunham de sala de ordenha do tipo canalizada nas propriedades do Oeste de SC, e as demais possuíam sala de ordenha mecânica do tipo balde ao pé. Observações semelhantes foram encontradas no Município de Nova Erechim.

Praticamente todas $(99,1 \%$ - 113/114) as propriedades de Nova Erechim realizaram um ou mais procedimentos para controle de mastite no rebanho, o que deve estar relacionado ao fato das empresas de laticínios da região realizarem 
testes de controle de qualidade do leite como rotina, e incentivarem o produtor através da valorização do leite pela melhor qualidade obtida (WINCK, 2012). Adicionalmente, 98,3\% (112/114) das propriedades realizavam contagem de células somáticas/contagem bacteriana total (CCS/CBT); 90,4\% (103/114) realizaram pós dipping; $86 \%$ (98/114) aplicavam bisnagas intramamárias como tratamento preventivo às mastites em vacas secas, 74,6\% (85/114) realizaram o teste California Mastitis Test (CMT); 54,4\% (62/114) realizaram pré dipping e 38,6\% (44/114) utilizaram caneca de fundo escuro. Observou-se que 1,7\% (2/114) das propriedades não realizavam CCS/CBT, possivelmente por não venderem seu produto às empresas de laticínios da região.

Dentre as propriedades que utilizavam antibióticos em vacas secas como tratamento preventivo a ocorrência de mastite (86\% - 98/114), 78,1\% (89/114) realizam o tratamento em todas as fêmeas no momento da secagem do leite (pré parto), enquanto $7,9 \%(9 / 114)$ aplicavam antibióticos somente nas fêmeas mais produtivas do rebanho, por acreditar que a presença de leite residual nessas vacas facilitaria a ocorrência de mastite. Winck e Thaler Neto (2012) observaram que 37\% das propriedades realizavam tratamento intramamário das fêmeas no período seco em rebanhos do Paraná e Santa Catarina.

Werncke et al. (2016) destacaram que $26 \%$ das propriedades do sul de SC não utilizam pré dipping, 50\% não utilizam pós dipping e 38,0\% não faziam terapia da vaca seca. Observa-se que há maior adesão dos produtores do Sul do Estado na utilização do pré dipping, enquanto o pós dipping e o manejo de vacas secas são mais comumente realizados no Oeste do Estado, como mostrado nas propriedades do município de Nova Erechim.

Winck e Thaler Neto (2012) relataram que o pré dipping foi utilizado por $25 \%$ dos produtores de diferentes regiões de Santa Catarina, enquanto o pós dipping tinha maior adesão (49\%). Os autores relataram ainda que $60 \%$ realizavam o teste da caneca de fundo preto, $51 \%$ o teste CMT e 37\% das propriedades realizavam tratamento intramamário das fêmeas no período seco. Manske et al., (2017) destacaram a importância do manejo de ordenha para a qualidade microbiológica do leite obtido e na prevenção de infecções intramamárias.

Das propriedades estudadas, 99,1\% (113/114) receberam pagamento pela qualidade do leite e 28,9\% (33/114) dos produtores participavam de alguma cooperativa ou associação, independentemente do destino da comercialização do leite produzido. A proporção de pagamento por qualidade do leite e a realização de controle de mastite foi a mesma $(99,1 \%$ - 113/114) nas propriedades de Nova Erechim, reforçando o fato que a comercialização do leite é realizada às empresas de laticínios da região (WINCK, 2012).

A inseminação artificial (IA) é utilizada em 78,95\% (90/114) das propriedades estudadas, sendo que 33,3\% (30/90) delas utilizam sêmen fornecido por centrais, $32,2 \%$ (29/90) pela prefeitura e 34,4\% (31/90) de ambos. No entanto, em nenhuma das propriedades constatou-se a presença de rufião como auxiliar na detecção do estro (Tabela 4). A porcentagem de utilização da IA observada neste estudo pode estar relacionada ao fornecimento gratuito de sêmen pela prefeitura municipal de Nova Erechim, que incentiva a adoção da técnica, fomentando o uso da IA nos rebanhos (NOVA ERECHIM, 2018). 
TABELA 4. Perfil reprodutivo/IA nos rebanhos das propriedades leiteiras do Município de Nova Erechim, Estado de Santa Catarina.

\begin{tabular}{|c|c|c|c|c|c|c|}
\hline \multirow{2}{*}{\multicolumn{2}{|c|}{ Parâmetros avaliados }} & \multicolumn{5}{|c|}{ Tamanho da Propriedade (Hectares) } \\
\hline & & Até 10 & $10,1-20$ & $20,1-30$ & $\begin{array}{c}\text { Maior que } \\
30\end{array}$ & Total \\
\hline \multicolumn{2}{|l|}{ Uso da IA (\%) } & $\begin{array}{c}78,6 \\
(22 / 28)\end{array}$ & $\begin{array}{c}80,0 \\
(40 / 50)\end{array}$ & $\begin{array}{c}77,8 \\
(21 / 27)\end{array}$ & $\begin{array}{l}77,8 \\
(7 / 9)\end{array}$ & $\begin{array}{c}78,95 \\
(90 / 114)\end{array}$ \\
\hline \multicolumn{2}{|c|}{$\begin{array}{l}\text { Conhecimento das vantagens } \\
\text { da IA (\%) }\end{array}$} & $\begin{array}{c}60,7 \\
(17 / 28)\end{array}$ & $\begin{array}{c}78,0 \\
(39 / 50)\end{array}$ & $\begin{array}{c}77,8 \\
(21 / 27)\end{array}$ & $\begin{array}{l}66,7 \\
(6 / 9)\end{array}$ & $\begin{array}{c}92,2 \\
(83 / 90)\end{array}$ \\
\hline \multicolumn{2}{|c|}{$\begin{array}{l}\text { Dificuldade realização da IA } \\
(\%)\end{array}$} & $\begin{array}{l}28,6 \\
(8 / 28)\end{array}$ & $\begin{array}{c}22,0 \\
(11 / 50)\end{array}$ & $\begin{array}{c}18,5 \\
(5 / 27)\end{array}$ & $\begin{array}{l}33,3 \\
(3 / 9)\end{array}$ & $\begin{array}{r}23,7( \\
27 / 114)\end{array}$ \\
\hline \multirow[t]{3}{*}{$\begin{array}{l}\text { Origem do } \\
\text { Sêmen }\end{array}$} & Central (\%) & $\begin{array}{c}36,4 \\
(8 / 22)\end{array}$ & $\begin{array}{c}30,0 \\
(12 / 40)\end{array}$ & $\begin{array}{c}38,1 \\
(8 / 21)\end{array}$ & $\begin{array}{l}28,6 \\
(2 / 7)\end{array}$ & $\begin{array}{c}33,3 \\
(30 / 90) \\
\end{array}$ \\
\hline & Prefeitura (\%) & $\begin{array}{c}40,9 \\
(9 / 22)\end{array}$ & $\begin{array}{c}32,5 \\
(13 / 40)\end{array}$ & $\begin{array}{l}28,6 \\
(6 / 21)\end{array}$ & $\begin{array}{l}14,3 \\
(1 / 7)\end{array}$ & $\begin{array}{c}32,2 \\
(29 / 90)\end{array}$ \\
\hline & $\begin{array}{l}\text { Central e } \\
\text { Prefeitura (\%) }\end{array}$ & $\begin{array}{l}22,7 \\
(5 / 22)\end{array}$ & $\begin{array}{c}37,5 \\
(15 / 40)\end{array}$ & $\begin{array}{l}33,3 \\
(7 / 21)\end{array}$ & $\begin{array}{l}57,1 \\
(4 / 7)\end{array}$ & $\begin{array}{c}34,4 \\
(31 / 90)\end{array}$ \\
\hline \multicolumn{2}{|c|}{ Uso de sêmen sexado (\%) } & $\begin{array}{c}4,5 \\
(1 / 22)\end{array}$ & $\begin{array}{c}10,0 \\
(4 / 40)\end{array}$ & $\begin{array}{c}42,9 \\
(9 / 21)\end{array}$ & $\begin{array}{l}28,6 \\
(2 / 7)\end{array}$ & $\begin{array}{c}17,8 \\
(16 / 90)\end{array}$ \\
\hline \multirow[t]{2}{*}{$\begin{array}{l}\text { Escolha do } \\
\text { Sêmen }\end{array}$} & Própria (\%) & $\begin{array}{c}90,9 \\
(20 / 22)\end{array}$ & $\begin{array}{c}60,0 \\
(24 / 40)\end{array}$ & $\begin{array}{l}33,3 \\
(7 / 21)\end{array}$ & $\begin{array}{l}42,9 \\
(3 / 7)\end{array}$ & $\begin{array}{c}60,0 \\
(54 / 90)\end{array}$ \\
\hline & Técnico (\%) & $\begin{array}{c}9,1 \\
(2 / 22)\end{array}$ & $\begin{array}{c}40,0 \\
(16 / 40)\end{array}$ & $\begin{array}{c}66,7 \\
(14 / 21)\end{array}$ & $\begin{array}{l}57,1 \\
(4 / 7)\end{array}$ & $\begin{array}{c}40,0 \\
(36 / 90)\end{array}$ \\
\hline \multicolumn{2}{|c|}{$\begin{array}{l}\text { Realização acasalamento } \\
\text { programado (\%) }\end{array}$} & $\begin{array}{c}18,2 \\
(4 / 22)\end{array}$ & $\begin{array}{c}35,0 \\
(14 / 40)\end{array}$ & $\begin{array}{c}52,4 \\
(11 / 21)\end{array}$ & $\begin{array}{l}42,9 \\
(3 / 7)\end{array}$ & $\begin{array}{c}35,6 \\
(32 / 90)\end{array}$ \\
\hline \multicolumn{2}{|c|}{$\begin{array}{l}\text { Utilização outras biotécnicas } \\
\text { reprodutivas (\%) }\end{array}$} & $\begin{array}{l}28,6 \\
(8 / 28)\end{array}$ & $\begin{array}{c}38,0 \\
(19 / 50)\end{array}$ & $\begin{array}{l}33,3 \\
(9 / 27)\end{array}$ & $\begin{array}{l}22,2 \\
(2 / 9)\end{array}$ & $\begin{array}{c}33,3 \\
(38 / 114)\end{array}$ \\
\hline \multicolumn{2}{|c|}{$\begin{array}{l}\text { Presença de rufião na } \\
\text { propriedade (\%) }\end{array}$} & $\begin{array}{c}0,0 \\
(0 / 22)\end{array}$ & $\begin{array}{c}0,0 \\
(0 / 40)\end{array}$ & $\begin{array}{c}0,0 \\
(0 / 21)\end{array}$ & $\begin{array}{c}0,0 \\
(0 / 7)\end{array}$ & $\begin{array}{c}0,0 \\
(0 / 90)\end{array}$ \\
\hline \multicolumn{2}{|c|}{$\begin{array}{l}\text { Inseminador na propriedade } \\
(\%)\end{array}$} & $\begin{array}{c}45,4 \\
(10 / 22)\end{array}$ & $\begin{array}{c}42,5 \\
(17 / 40)\end{array}$ & $\begin{array}{c}52,4 \\
(11 / 21)\end{array}$ & $\begin{array}{l}57,1 \\
(4 / 7)\end{array}$ & $\begin{array}{c}46,7 \\
(42 / 90)\end{array}$ \\
\hline \multirow{4}{*}{$\begin{array}{l}\text { Tempo } \\
\text { capacitação do } \\
\text { inseminador } \\
(\%)\end{array}$} & Até um ano & $\begin{array}{c}10,0 \\
(1 / 10)\end{array}$ & $\begin{array}{l}11,8 \\
(2 / 17)\end{array}$ & $\begin{array}{c}18,2 \\
(2 / 11)\end{array}$ & $\begin{array}{l}25,0 \\
(1 / 4)\end{array}$ & $\begin{array}{c}14,3 \\
(6 / 42)\end{array}$ \\
\hline & $\begin{array}{l}\text { De } 2 \text { a } 5 \\
\text { anos }\end{array}$ & $\begin{array}{l}80,0 \\
(8 / 10)\end{array}$ & $\begin{array}{l}52,9 \\
(9 / 17)\end{array}$ & $\begin{array}{c}18,2 \\
(2 / 11)\end{array}$ & $\begin{array}{c}0,0 \\
(0 / 4)\end{array}$ & $\begin{array}{c}45,2 \\
(19 / 42)\end{array}$ \\
\hline & $\begin{array}{l}\text { De } 6 \text { a } 10 \\
\text { anos }\end{array}$ & $\begin{array}{c}10,0 \\
(1 / 10)\end{array}$ & $\begin{array}{c}23,5 \\
(4 / 17)\end{array}$ & $\begin{array}{c}45,4 \\
(5 / 11)\end{array}$ & $\begin{array}{c}0,0 \\
(0 / 4)\end{array}$ & $\begin{array}{c}23,8 \\
(10 / 42)\end{array}$ \\
\hline & $\begin{array}{l}\text { De } 11 \text { ou } \\
\text { mais }\end{array}$ & $\begin{array}{l}0,0( \\
0 / 10)\end{array}$ & $\begin{array}{c}11,8 \\
(2 / 17)\end{array}$ & $\begin{array}{c}18,2 \\
(2 / 11)\end{array}$ & $\begin{array}{l}75,0 \\
(3 / 4)\end{array}$ & $\begin{array}{l}16,7 \\
(7 / 42)\end{array}$ \\
\hline \multirow[t]{3}{*}{$\begin{array}{l}\text { Botijão de } \\
\text { Sêmen }\end{array}$} & Próprio (\%) & $\begin{array}{c}36,4 \\
(8 / 22)\end{array}$ & $\begin{array}{c}25,0 \\
(10 / 40)\end{array}$ & $\begin{array}{c}47,6 \\
(10 / 21)\end{array}$ & $\begin{array}{l}42,9 \\
(3 / 7)\end{array}$ & $\begin{array}{c}34,4 \\
(31 / 90)\end{array}$ \\
\hline & $\begin{array}{l}\text { Comunitário } \\
(\%)\end{array}$ & $\begin{array}{c}18,2 \\
(4 / 22)\end{array}$ & $\begin{array}{c}35,0 \\
(14 / 40)\end{array}$ & $\begin{array}{c}33,3 \\
(7 / 21)\end{array}$ & $\begin{array}{l}42,9 \\
(3 / 7)\end{array}$ & $\begin{array}{c}31,1 \\
(28 / 90)\end{array}$ \\
\hline & Não possui (\%) & $\begin{array}{c}45,4 \\
(10 / 22)\end{array}$ & $\begin{array}{c}40,0 \\
(16 / 40)\end{array}$ & $\begin{array}{c}19,0 \\
(4 / 21)\end{array}$ & $\begin{array}{l}14,3 \\
(1 / 7)\end{array}$ & $\begin{array}{c}34,4 \\
(31 / 90)\end{array}$ \\
\hline
\end{tabular}

As vantagens apresentadas pela $I A$, ofertadas a preço accessível, fazem dessa tecnologia de grande valia, independentemente do tamanho do rebanho. Mesmo com os benefícios apresentados pela Associação Brasileira de Inseminação Artificial (ASBIA, 2017), estima-se que apenas 6,2\% das fêmeas bovinas leiteiras são inseminadas no Brasil. Santos Junior et al. (2016) relataram que 36,08\% (92/255) das propriedades de Realeza - PR utilizaram IA, todas com sêmen proveniente de centrais de IA. Como justificativa da utilização da IA, 92,2\% dos produtores (83/90) citaram ao menos uma das reais vantagens da técnica, sendo que $21,1 \%$ (19/90) ainda destacaram todas as vantagens expostas, sendo 
melhoramento genético, facilidade de manejo, diminuição na transmissão de doenças, utilização de touros provados, baixo custo, economia e praticidade.

Nas propriedades estudadas de Nova Erechim, 17,8\% (16/90) utilizaram sêmen sexado, sendo a maior frequência dessa utilização observada em propriedades de 20,1 a 30 ha (42,9\% - 9/21). Observou-se ainda, que 40\% (36/90) das propriedades que utilizam a IA, escolheram o sêmen por técnico qualificado (médico veterinário e/ou vendedor treinado), sendo que em 90,9\% (20/22) das propriedades com até 10 ha, a escolha do sêmen foi por conta própria, sem necessariamente associar características técnicas para esse fim. Adicionalmente, $35,6 \%$ (32/90) das propriedades programaram o acasalamento prévio dos animais, a fim de melhorar a genética do rebanho e corrigir características indesejáveis existentes. A escolha do sêmen tem efeito direto sobre a progênie, possibilitando correção de características indesejadas ou defeitos da fêmea para as próximas gerações. Portanto as características futuras do rebanho dependem diretamente dos cruzamentos utilizados (ALENCAR, 2004).

A utilização de monta natural (MN) foi observada em 38,6\% (44/114) das propriedades de Nova Erechim - SC, sendo que 6,8\% (3/44) relataram utilizar touro somente para repasse na repetição de estro após IA, sendo a anotação de cobertura era realizada em $86,4 \%$ (38/44) das propriedades que utilizavam MN (Tabela 5).

TABELA 5. Perfil reprodutivo/MN nos rebanhos das propriedades leiteiras do Município de Nova Erechim, Estado de Santa Catarina.

\begin{tabular}{|c|c|c|c|c|c|c|}
\hline \multirow{2}{*}{\multicolumn{2}{|c|}{ Parâmetros avaliados }} & \multicolumn{5}{|c|}{ Tamanho da Propriedade (Hectares) } \\
\hline & & Até 10 & $10,1-20$ & $20,1-30$ & $\begin{array}{c}\text { Maior } \\
\text { que } 30\end{array}$ & Total \\
\hline \multicolumn{2}{|l|}{ Uso da MN (\%) } & $\begin{array}{c}46,4 \\
(13 / 28)\end{array}$ & $\begin{array}{c}36,0 \\
(18 / 50)\end{array}$ & $\begin{array}{c}33,3 \\
(9 / 27)\end{array}$ & $\begin{array}{l}44,4 \\
(4 / 9)\end{array}$ & $\begin{array}{c}38,6 \\
(44 / 114)\end{array}$ \\
\hline \multicolumn{2}{|c|}{ Existe touro na propriedade (\%) } & $\begin{array}{c}76,9 \\
(10 / 13)\end{array}$ & $\begin{array}{c}100 \\
(18 / 18)\end{array}$ & $\begin{array}{l}100 \\
(9 / 9)\end{array}$ & $\begin{array}{l}100 \\
(4 / 4)\end{array}$ & $\begin{array}{c}93,2 \\
(41 / 44)\end{array}$ \\
\hline \multirow[t]{2}{*}{$\begin{array}{l}\text { Origem } \\
\text { Touro }\end{array}$} & Própria (\%) & $\begin{array}{c}23,1 \\
(3 / 13)\end{array}$ & $\begin{array}{l}38,9 \\
(7 / 18)\end{array}$ & $\begin{array}{l}33,3 \\
(3 / 9)\end{array}$ & $\begin{array}{l}50,0 \\
(2 / 4)\end{array}$ & $\begin{array}{c}34,1 \\
(15 / 44)\end{array}$ \\
\hline & Terceiros (\%) & $\begin{array}{l}69,2 \\
(9 / 13)\end{array}$ & $\begin{array}{c}61,1 \\
(11 / 18)\end{array}$ & $\begin{array}{l}66,7 \\
(6 / 9)\end{array}$ & $\begin{array}{l}50,0 \\
(2 / 4)\end{array}$ & $\begin{array}{c}63,6 \\
(28 / 44)\end{array}$ \\
\hline \multirow{2}{*}{$\begin{array}{l}\text { Raça do touro } \\
\text { em relação as } \\
\text { vacas (\%) }\end{array}$} & Mesma Raça & $\begin{array}{c}61,5 \\
(8 / 13)\end{array}$ & $\begin{array}{c}61,1 \\
(11 / 18)\end{array}$ & $\begin{array}{l}66,7 \\
(6 / 9)\end{array}$ & $\begin{array}{c}100 \\
(4 / 4)\end{array}$ & $\begin{array}{c}61,4 \\
(27 / 44)\end{array}$ \\
\hline & Outra Raça & $\begin{array}{c}38,5 \\
(5 / 13)\end{array}$ & $\begin{array}{l}38,9 \\
(7 / 18)\end{array}$ & $\begin{array}{l}33,3 \\
(3 / 9)\end{array}$ & $\begin{array}{c}0,0 \\
(0 / 4)\end{array}$ & $\begin{array}{c}34,1 \\
(15 / 44)\end{array}$ \\
\hline \multirow{3}{*}{$\begin{array}{l}\text { Permanece } \\
\text { com Fêmeas } \\
\text { (\%) }\end{array}$} & $\begin{array}{l}\text { Com todo o } \\
\text { Rebanho }\end{array}$ & $\begin{array}{c}38,5 \\
(5 / 13)\end{array}$ & $\begin{array}{l}27,8 \\
(5 / 18)\end{array}$ & $\begin{array}{l}55,6 \\
(5 / 9)\end{array}$ & $\begin{array}{l}75,0 \\
(3 / 4)\end{array}$ & $\begin{array}{c}40,9 \\
(18 / 44)\end{array}$ \\
\hline & $\begin{array}{l}\text { Novilhas e/ou } \\
\text { Vacas secas }\end{array}$ & $\begin{array}{c}23,1 \\
(3 / 13)\end{array}$ & $\begin{array}{c}33,3 \\
(6 / 18)\end{array}$ & $\begin{array}{l}33,3 \\
(3 / 9)\end{array}$ & $\begin{array}{l}0,0 \\
(0 / 4)\end{array}$ & $\begin{array}{l}20,5 \\
(9 / 44)\end{array}$ \\
\hline & Não permanece & $\begin{array}{c}38,5 \\
(5 / 13)\end{array}$ & $\begin{array}{c}38,9 \\
(7 / 18)\end{array}$ & $\begin{array}{l}11,1 \\
(1 / 9)\end{array}$ & $\begin{array}{l}50,0 \\
(2 / 4)\end{array}$ & $\begin{array}{c}38,6 \\
(17 / 44)\end{array}$ \\
\hline \multicolumn{2}{|c|}{$\begin{array}{l}\text { Manejo nutricional diferenciado } \\
\text { para touro }(\%)\end{array}$} & $\begin{array}{c}45,5 \\
(5 / 13)\end{array}$ & $\begin{array}{l}56,6 \\
(7 / 18)\end{array}$ & $\begin{array}{l}49,5 \\
(5 / 9)\end{array}$ & $\begin{array}{l}0,0 \\
(0 / 4)\end{array}$ & $\begin{array}{c}38,6 \\
(17 / 44)\end{array}$ \\
\hline \multicolumn{2}{|c|}{ Anotação de coberturas (\%) } & $\begin{array}{c}92,3 \\
(12 / 13)\end{array}$ & $\begin{array}{c}77,8 \\
(14 / 18)\end{array}$ & $\begin{array}{l}100,0 \\
(9 / 9)\end{array}$ & $\begin{array}{l}75,0 \\
(3 / 4)\end{array}$ & $\begin{array}{c}86,4 \\
(38 / 44)\end{array}$ \\
\hline \multirow{2}{*}{\multicolumn{2}{|c|}{$\begin{array}{l}\text { Realização de exame } \\
\text { andrológico no touro (\%) } \\
\text { Aceitaria realizar andrológico no } \\
\text { touro (\%) }\end{array}$}} & $\begin{array}{c}7,7 \\
(1 / 13)\end{array}$ & $\begin{array}{c}0,0 \\
(0 / 18)\end{array}$ & $\begin{array}{c}0,0 \\
(0 / 9)\end{array}$ & $\begin{array}{l}100,0 \\
(4 / 4)\end{array}$ & $\begin{array}{c}2,3 \\
(1 / 44)\end{array}$ \\
\hline & & $\begin{array}{c}23,1 \\
(3 / 13)\end{array}$ & $\begin{array}{c}16,7 \\
(3 / 18)\end{array}$ & $\begin{array}{l}11,1 \\
(1 / 9)\end{array}$ & $\begin{array}{l}75,0 \\
(3 / 4)\end{array}$ & $\begin{array}{c}22,7 \\
(10 / 44)\end{array}$ \\
\hline
\end{tabular}

Contrastando com o observado nas propriedades de Nova Erechim, Santos Junior et al. (2016) relataram que a MN foi utilizada em 63,92\% (163/255) das 
propriedades de Realeza - PR, sendo em 6,27\% (16/255) dessas a utilização era em conjunto com a IA. Das propriedades que utilizavam da MN, 93,87 \% (153/163) possuíam reprodutor próprio, sendo 38,04\% (62/153) proveniente da própria propriedade, e $66,0 \%$ (101/153) adquiridos de terceiros. Em 68,10\% (111/163) delas o touro permanecia junto com as fêmeas, e a anotação de coberturas era realizada em 50,92 \% (83/163) das propriedades. Observa-se que dentre as propriedades de Nova Erechim que utilizaram touro em $\mathrm{MN}$, somente 2,3\% (1/44) realizaram avaliação andrológica, e somente $22,7 \%$ (10/44) dos produtores aceitariam submeter gratuitamente esses animais ao exame andrológico.

A utilização de outra biotécnica reprodutiva, como a IATF e/ou uso de transferência de embriões, foi observada em 33,3\% (38/114) das propriedades estudadas, sem apresentar variação entre os tamanhos das propriedades (Tabela 4). Resultados inferiores foram relatados por Santos Junior et al. (2016), nos quais a IATF foi a única biotécnica utilizada, observada em apenas 2,75\% (7/255) das propriedades de Realeza-PR.

Das propriedades estudadas, $88,6 \%(101 / 114)$ utilizaram a rotação de pastagens como método de manejo nutricional das vacas, independentemente do tamanho da propriedade, excluindo-se aquelas cujos animais encontravam-se mantidos em sistema de confinamento (compost barn e freestall), que corresponderam a 9,65\% das propriedades (11/114) (Tabela 6).

TABELA 6. Manejo nutricional das fêmeas utilizado das propriedades leiteiras do município de Nova Erechim, Estado de Santa Catarina.

\begin{tabular}{|c|c|c|c|c|c|c|}
\hline \multirow{2}{*}{\multicolumn{2}{|c|}{ Parâmetros avaliados }} & \multicolumn{5}{|c|}{ Tamanho da Propriedade (Hectares) } \\
\hline & & Até 10 & $\begin{array}{c}10,1- \\
20\end{array}$ & $\begin{array}{c}20,1- \\
30\end{array}$ & $\begin{array}{l}\text { Maior } \\
\text { que } 30\end{array}$ & Total \\
\hline \multicolumn{2}{|c|}{ Uso de rotação de pastagens (\%) } & $\begin{array}{c}89,3 \\
(25 / 28)\end{array}$ & $\begin{array}{c}90,0 \\
(45 / 50)\end{array}$ & $\begin{array}{c}88,9 \\
(24 / 27)\end{array}$ & $\begin{array}{l}77,8 \\
(7 / 9)\end{array}$ & $\begin{array}{c}88,6 \\
(101 / 114)\end{array}$ \\
\hline \multicolumn{2}{|c|}{ Suplementação de volumoso (\%) } & $\begin{array}{c}100,0 \\
(28 / 28)\end{array}$ & $\begin{array}{c}100,0 \\
(50 / 50)\end{array}$ & $\begin{array}{l}100,0 \\
(27 / 27)\end{array}$ & $\begin{array}{l}100,0 \\
(9 / 9)\end{array}$ & $\begin{array}{c}100,0 \\
(114 / 114)\end{array}$ \\
\hline \multirow[t]{3}{*}{$\begin{array}{l}\text { Suplementação } \\
\text { ração }\end{array}$} & $\begin{array}{l}\text { Balanceada } \\
(\%)\end{array}$ & $\begin{array}{c}10,7 \\
(3 / 28)\end{array}$ & $\begin{array}{c}26,0 \\
(13 / 50)\end{array}$ & $\begin{array}{c}33,3 \\
(9 / 27)\end{array}$ & $\begin{array}{l}33,3 \\
(3 / 9)\end{array}$ & $\begin{array}{c}24,6 \\
(28 / 114)\end{array}$ \\
\hline & $\begin{array}{l}\text { Estimada } \\
(\%)\end{array}$ & $\begin{array}{c}46,4 \\
(13 / 28)\end{array}$ & $\begin{array}{c}58,0 \\
(29 / 50)\end{array}$ & $\begin{array}{c}59,3 \\
(16 / 27)\end{array}$ & $\begin{array}{l}33,3 \\
(3 / 9)\end{array}$ & $\begin{array}{c}53,5 \\
(61 / 114)\end{array}$ \\
\hline & $\begin{array}{l}\text { Equivalente } \\
(\%)\end{array}$ & $\begin{array}{c}35,7 \\
(10 / 28)\end{array}$ & $\begin{array}{c}10,0 \\
(5 / 50)\end{array}$ & $\begin{array}{c}7,4 \\
(2 / 27)\end{array}$ & $\begin{array}{l}33,3 \\
(3 / 9)\end{array}$ & $\begin{array}{c}17,5 \\
(20 / 114)\end{array}$ \\
\hline \multirow[t]{3}{*}{$\begin{array}{l}\text { Suplementação } \\
\text { sal mineral }\end{array}$} & $\begin{array}{ll}\text { Ad } & \text { libitum } \\
(\%) & \end{array}$ & $\begin{array}{c}42,9 \\
(12 / 28)\end{array}$ & $\begin{array}{c}32,0 \\
(16 / 50)\end{array}$ & $\begin{array}{c}33,3 \\
(9 / 27)\end{array}$ & $\begin{array}{l}66,7 \\
(6 / 9)\end{array}$ & $\begin{array}{c}37,7 \\
(43 / 114)\end{array}$ \\
\hline & $\begin{array}{l}\text { Estimado } \\
(\%)\end{array}$ & $\begin{array}{c}42,9 \\
(12 / 28)\end{array}$ & $\begin{array}{c}48,0 \\
(24 / 50)\end{array}$ & $\begin{array}{c}51,9 \\
(14 / 27)\end{array}$ & $\begin{array}{c}0,0 \\
(0 / 9)\end{array}$ & $\begin{array}{c}43,9 \\
(50 / 114)\end{array}$ \\
\hline & $\begin{array}{l}\text { Balanceado } \\
(\%)\end{array}$ & $\begin{array}{c}7,1 \\
(2 / 28)\end{array}$ & $\begin{array}{c}18,0 \\
(9 / 50)\end{array}$ & $\begin{array}{c}14,8 \\
(4 / 27)\end{array}$ & $\begin{array}{l}33,3 \\
(3 / 9)\end{array}$ & $\begin{array}{c}15,8 \\
(18 / 114)\end{array}$ \\
\hline
\end{tabular}

Aproximadamente $90 \%$ das propriedades leiteiras de Nova Erechim desenvolveram a atividade leiteira sob pastejo, sendo que as pastagens corresponderam a $85 \%$ da dieta, corroborando com o encontrado por Manske et al. (2017) em estudo realizado na mesma região. Chambela Neto et al. (2018) relataram que a deficiência de pastagens, ou a oferta inadequada, acarreta problemas nutricionais fortemente relacionados a produtividade de rebanhos leiteiros. No entanto, a deficiência de pastagem não foi observada nas propriedades 
leiteiras de Nova Erechim - SC, talvez pela suplementação volumosa fornecida as fêmeas de todas as propriedades estudadas.

Werncke et al. (2016) relataram que o sistema de produção predominante no sul de SC também é baseado em pastagem com suplementação concentrada e forragem conservada (silagem), associada a rotação de pastagens, semelhante ao manejo nutricional observado em Nova Erechim. A nutrição adequada é indispensável para atingir adequados índices reprodutivos, uma vez que a fêmea bovina irá reproduzir quando houver energia disponível acima das necessidades de mantença e de produção leiteira, sob balanço energético positivo (BERGAMASCHI et al., 2010). O manejo nutricional observado nas propriedades de Nova Erechim possivelmente esteja adequado, pois a produção média de leite/animal/dia é superior ao descrito na literatura (CASARI; TORMEM, 2011; SANTOS JÚNIOR et al., 2016; WERNCKE et al., 2016).

O sucesso e rentabilidade na produção leiteira depende da qualidade da água utilizada na atividade, garantindo a sanidade do rebanho e a segurança alimentar dos consumidores. Além disso, há relação direta entre a vida útil de equipamentos e a ocorrência de doenças nos animais com a água utilizada (LEIRA et al., 2018). Nesse contexto, as características da água das propriedades de Nova Erechim encontram-se detalhadas na Tabela 7.

TABELA 7. Características da água das propriedades leiteiras do Município de Nova Erechim, Estado de Santa Catarina.

\begin{tabular}{|c|c|c|c|c|c|c|c|}
\hline \multirow{2}{*}{\multicolumn{3}{|c|}{ Parâmetros avaliados }} & \multicolumn{5}{|c|}{ Tamanho da Propriedade (Hectares) } \\
\hline & & & \multirow{2}{*}{$\begin{array}{c}\text { Até } 10 \\
\\
60,7 \\
(17 / 28)\end{array}$} & \multirow{2}{*}{$\begin{array}{c}10,1-20 \\
44,0 \\
(22 / 50)\end{array}$} & \multirow{2}{*}{$\begin{array}{c}20,1-30 \\
63,0 \\
(17 / 27)\end{array}$} & \multirow{2}{*}{$\begin{array}{c}\text { Maior } \\
\text { que } 30 \\
55,6 \\
(5 / 9)\end{array}$} & \multirow{2}{*}{$\begin{array}{c}\text { Total } \\
53,5 \\
(61 / 114)\end{array}$} \\
\hline \multirow[t]{4}{*}{$\begin{array}{l}\text { Origem } \\
\text { da água }\end{array}$} & \multicolumn{2}{|l|}{ Poço (\%) } & & & & & \\
\hline & \multicolumn{2}{|c|}{ Nascente (\%) } & $\begin{array}{c}42,9 \\
(12 / 28)\end{array}$ & $\begin{array}{c}54,0 \\
(27 / 50)\end{array}$ & $\begin{array}{c}33,3 \\
(9 / 27)\end{array}$ & $\begin{array}{l}55,6 \\
(5 / 9)\end{array}$ & $\begin{array}{c}46,5 \\
(53 / 114)\end{array}$ \\
\hline & \multicolumn{2}{|l|}{ Rio (\%) } & $\begin{array}{c}3,6 \\
(1 / 28)\end{array}$ & $\begin{array}{c}6,0 \\
(3 / 50)\end{array}$ & $\begin{array}{c}3,7 \\
(1 / 27)\end{array}$ & $\begin{array}{c}0,0 \\
(0 / 9)\end{array}$ & $\begin{array}{l}4,4 \\
(5 / 114)\end{array}$ \\
\hline & \multicolumn{2}{|l|}{ Cisterna (\%) } & $\begin{array}{c}3,6 \\
(1 / 28)\end{array}$ & $\begin{array}{c}2,0 \\
(1 / 50)\end{array}$ & $\begin{array}{c}3,7 \\
(1 / 27)\end{array}$ & $\begin{array}{c}0,0 \\
(0 / 9)\end{array}$ & $\begin{array}{c}2,6 \\
(3 / 114)\end{array}$ \\
\hline \multirow[t]{6}{*}{$\begin{array}{l}\text { Qualidade } \\
\text { da água }\end{array}$} & \multicolumn{2}{|c|}{ Realiza análise (\%) } & $\begin{array}{c}96,4 \\
(27 / 28)\end{array}$ & $\begin{array}{c}76,0 \\
(38 / 50)\end{array}$ & $\begin{array}{c}85,2 \\
(23 / 27)\end{array}$ & $\begin{array}{l}77,8 \\
(7 / 9)\end{array}$ & $\begin{array}{c}83,3 \\
(95 / 114)\end{array}$ \\
\hline & \multirow[t]{4}{*}{$\begin{array}{l}\text { Frequência } \\
\text { análise (\%) }\end{array}$} & $\begin{array}{l}\text { Quando abriu } \\
\text { o poço }\end{array}$ & $\begin{array}{c}0,0 \\
(0 / 28)\end{array}$ & $\begin{array}{c}2,0 \\
(1 / 50)\end{array}$ & $\begin{array}{c}0,0 \\
(0 / 27)\end{array}$ & $\begin{array}{c}0,0 \\
(0 / 9)\end{array}$ & $\begin{array}{c}0,9 \\
(1 / 114)\end{array}$ \\
\hline & & $\begin{array}{l}\text { Até } \\
\text { vez/ano }\end{array}$ & $\begin{array}{c}60,7 \\
(17 / 28)\end{array}$ & $\begin{array}{c}54,0 \\
(27 / 50)\end{array}$ & $\begin{array}{c}55,6 \\
(15 / 27)\end{array}$ & $\begin{array}{l}66,7 \\
(6 / 9)\end{array}$ & $\begin{array}{c}57,0 \\
(65 / 114)\end{array}$ \\
\hline & & $\begin{array}{l}\text { Mais duas } \\
\text { vezes/ano }\end{array}$ & $\begin{array}{c}28,6 \\
(8 / 28)\end{array}$ & $\begin{array}{l}18,0 \\
(9 / 50)\end{array}$ & $\begin{array}{c}18,5 \\
(5 / 27)\end{array}$ & $\begin{array}{l}11,1 \\
(1 / 9)\end{array}$ & $\begin{array}{c}20,2 \\
(23 / 114)\end{array}$ \\
\hline & & $\begin{array}{l}\text { Não lembra o } \\
\text { tempo }\end{array}$ & $\begin{array}{c}7,1 \\
(2 / 28)\end{array}$ & $\begin{array}{c}2,0 \\
(1 / 50)\end{array}$ & $\begin{array}{c}11,1 \\
(3 / 27)\end{array}$ & $\begin{array}{c}0,0 \\
(0 / 9)\end{array}$ & $\begin{array}{l}5,3 \\
(6 / 114)\end{array}$ \\
\hline & \multicolumn{2}{|c|}{ Realiza tratamento (\%) } & $\begin{array}{c}53,6 \\
(15 / 28)\end{array}$ & $\begin{array}{c}56,0 \\
(28 / 50)\end{array}$ & $\begin{array}{c}59,3 \\
(16 / 27)\end{array}$ & $\begin{array}{l}22,2 \\
(2 / 9)\end{array}$ & $\begin{array}{c}53,5 \\
(61 / 114)\end{array}$ \\
\hline
\end{tabular}

Entre as propriedades de Nova Erechim, para realizar as atividades relacionadas à produção leiteira e a ordenha, 53,5\% (61/114) delas utilizavam água proveniente de poço artesiano, 46,5\% (53/114) de nascentes, 4,4\% (5/114) de rios e 2,6\% (3/114) possuíam cisternas de armazenamento de água para produção leiteira (Tabela 7). Nenhuma propriedade utilizava água de distribuição urbana. Das propriedades estudadas, 83,3\% (95/114) efetuavam a análise da água, sendo que $57,0 \%(65 / 114)$ realizavam análise uma vez ao ano, 20,2\% (23/114) duas ou mais 
vezes, 5,3\% (6/114) já fizeram análise em algum momento, 0,9\% (1/114) analisaram a água somente quando abriu a fonte e $16,67 \%$ (19/114) nunca analisaram a água. Dessas propriedades, 53,5\% (61/114) fizeram tratamento, todos à base de cloro, na água destinada a atividade leiteira. Werncke et al. (2016) destacaram que $96 \%$ dos participantes de seu estudo não realizavam tratamento na água utilizada no processo de ordenha e higienização dos equipamentos, o que afetava negativamente a eficiência e a qualidade do leite produzido.

João et al. (2011) coletaram amostras das fontes de água nas propriedades do meio oeste de SC e constataram que 95\% (76/80) dessas apresentaram coliformes totais e $24 \%(18 / 80)$ apresentaram coliformes fecais, o que representa alto risco à saúde humana e animal para a região. Adicionalmente, os autores relataram que $100 \%$ (22/22) das águas provenientes de poços artesianos e $90 \%$ (52/58) das águas provenientes de fonte/nascentes não eram submetidas a nenhum tratamento prévio. Também Ramires et al. (2009) destacam que grande parte das propriedades de seu estudo não dispunham de fontes de água adequadas, indicando a necessidade da criação de programas que tragam melhorias a esse setor, pois a baixa qualidade da água pode ser via de transmissão de doenças além de comprometer a vida útil dos equipamentos (RAMIRES et al. 2009). Neste estudo, observou-se que as propriedades de Nova Erechim possuem a necessidade óbvia de adoção de medidas e incentivos para tratamento da água, a fim de garantir qualidade do leite e da saúde dos envolvidos.

\section{CONCLUSÃO}

A produção de leite em Nova Erechim ocorre predominantemente em pequenas propriedades, que possuem a bovinocultura leiteira como principal atividade agrícola, explorando principalmente bovinos da raça Holandêsa em sistemas de produção a pasto.

Os manejos empregados na produção são similares, independentemente do tamanho da propriedade, com destaque ao emprego da inseminação artificial na reprodução das fêmeas. Porém outras biotécnicas reprodutivas ainda são pouco aplicadas.

As propriedades necessitam de maior conscientização quanto a importância do monitoramento da qualidade da água, assim como dos reprodutores utilizados, quando ocorre a monta natural das fêmeas.

\section{REFERÊNCIAS}

ALENCAR, M.M. Perspectivas para o Melhoramento Genético de Bovinos de Corte no Brasil. Embrapa, 2004, 14 p. Disponível em: https://ainfo.cnptia.embrapa.br/digital/bitstream/CPPSE/15172/1/PROCIMMA2004.00 003.pdf

ASBIA. Associação Brasileira de Inseminação Artificial. Relatório Index 2017, 37p. Disponível em: < http://www.asbia.org.br/wp-content/uploads/2018/10/INDEXASBIA-2017_completo.pdf>

BERGAMASCHI, M.A.C.M.A.; MACHADO, R.; BARBOSA, R.T. Eficiência reprodutiva das vacas leiteiras. Circular Técnica - Embrapa, São Carlos, SP, 2010. Disponível

em: https://www.infoteca.cnptia.embrapa.br/bitstream/doc/880245/1/Circular642.pdf> 
CASARI, P.; TORMEM, P. Atividade Leiteira, Agricultura Familiar e Desenvolvimento Regional: estudo de caso da Linha Tormem. Chapecó-SC. Revista Estudos do CEPE, Santa Cruz do Sul, n.34, p.139-171, 2011. Disponível em: <https://online.unisc.br/seer/index.php/cepe/article/view/936/1687>DOI:

<http://dx.doi.org/10.17058/cepe.v0i34.936>

CERON, A. Região Sul do Brasil lidera produção nacional de leite. Secretaria de Estado da Agricultura e da Pesca, 2016. Disponível em: <http://www.sc.gov.br/mais-sobre-agricultura-e-pesca/22772-regiao-sul-do-brasillidera-producao-nacional-de-leite>

CIDADE-BRASIL. Município de Nova Erechim. Cidade-Brasil, 2016. Disponível em: $<$ http://www.cidade-brasil.com.br/municipio-nova-erechim.html>

CHAMBELA NETO, A..; VIEIRA, G. H. S.; HADDADE, I. R.; ROSADO, T. L.; MELLO, B. L. B. Aplicação de novas tecnologias na bovinocultura leiteira. Incaper em Revista, v.9, p. 51-65, 2018. Disponível em: https://biblioteca.incaper.es.gov.br/digital/bitstream/123456789/3367/1/aplicacaoden ovastecnologiasnabovinoleiteira-mello.pdf

FERNANDES, R. S.; SILVA, A. M.; FALCÃO, R. P. A pluriatividade como fator de geração de renda para a agricultura familiar de Córrego Primavera, Rio Bananal, Espírito Santo, Brasil. Extensão Rural, DEAER - CCR - UFSM, Santa Maria, v.25, n.2, 2018. Disponível em:

< https://periodicos.ufsm.br/extensaorural/article/view/29969/pdf>

FISCHER, A.; SANTOS JUNIOR, S.; SCHNEM, S.; BERNARDI, I. Produção e Produtividade de Leite do Oeste Catarinense. RACE, Unoesc, v.10, n.2, p.337-362, $2011 . \quad$ Disponível

em: <http://editora.unoesc.edu.br/index.php/race/article/viewFile/1681/pdf>

IBGE. Produção da Pecuária Municipal 2016. IBGE - Instituto Brasileiro de Geografia e Estatística, Rio de Janeiro, 2016. Disponível em: <https://cidades.ibge.gov.br/brasil/sc/nova-erechim/pesquisa/18/16459>

JOÃO, J.H.; LIMA ROSA, C. A. V.; NETO, A. T.; ALMEIDA PICININ, L. C.; FUCK, J. J. et al. Qualidade da água utilizada na ordenha de propriedades leiteiras do Meio Oeste Catarinense, Brasil. Revista de Ciências Agroveterinárias. Lages, v.10, n.1, p. 9-15, 2011. Disponível em: http://www.revistas.udesc.br/index.php/agroveterinaria/article/viewFile/5264/3474

LEIRA, M. H.; BOTELHO, H. A.; SANTOS, H. C. A. S.; BARRETO, B. B.; BOTELHO, J. H. V. et al. Fatores que alteram a produção e a qualidade do leite: Revisão. Pubvet, v.12, n.5, a85, p.1-13., 2018. Disponível em: < http://www.pubvet.com.br/artigo/4780/fatores-que-alteram-a-produccedilatildeo-e-aqualidade-do-leite-revisatildeo> DOI https://doi.org/10.22256/pubvet.v12n5a85.1-13

MAKISHI, F.; VEIGA, J. P. C.; ZACARELI, M. A. Desenvolvimento local de comunidades rurais e suas implicações para as políticas públicas: Arranjos institucionais e diversificação da produção rural de pequena escala. Revista Política 
e Planejamento Regional, v. 3, n. 2, 221 a 241, 2016. Disponível em: <http://www.revistappr.com.br/artigos/publicados/Desenvolvimento-local-decomunidades-rurais-e-suas-Implicacoes-para-as-politicas-publicas-Arranjosinstitucionais-e-diversificacao-da-producao-rural-de-pequena-escala.pdf>

MANSKE, G.A.; RIGO, E.; SCHOGOR, A.L.B. Caracterização das Propriedades Rurais do Extremo Oeste de Santa Catarina. 7ํㅗㄴ SEPE - Seminário de Ensino, Pesquisa e Extensão, CED- UDESC, 2017. Disponível em: <http://udesc.br/arquivos/ceo/id_cpmenu/778/25_Mestrado_Eng_Ana_Luiza_Guil herme_Manske_ES_15190628358349_778.pdf>

MARCONDES, T. Síntese Anual da Agricultura de Santa Catarina 2015 - 2016. Centro de Socioeconômia e Planejamento Agrícola, p.116, 2016. Disponível em: <https://drive.google.com/file/d/1E47TVy52gY-XDJLhJROwPItjW9aK6RMB/view>

MEZZADRI, F. P. Leite -Análise da Conjuntura Agropecuária, Ano 2015/16.SEAB Secretaria de Estado da Agricultura e do Abastecimento. 2016, 15 p. Disponível em:<http://www.agricultura.pr.gov.br/arquivos/File/deral/Prognosticos/2016/bovinocul tura_de_leite_2016.pdf>

NEVES, B. M. C. Caracterização produtiva e aspectos sanitários relacionados à bovinocultura em Santa Catarina. 2014. Dissertação (Mestrado em Saúde Animal) - Faculdade de Agronomia e Medicina Veterinária, Universidade de Brasília, Brasília. Disponível em: <http://repositorio.unb.br/bitstream/10482/16584/1/2014_BidiahMarianoDaCostaNev es.pdf>

NOVA ERECHIM. 2018. SECRETARIA DA AGRICULTURA. Apresentação. Secretaria da Agricultura - Município de Nova Erechim. Disponível em: <http://www.novaerechim.sc.gov.br/estruturaorganizacional/hotsite/index/codHotsite/ 2614>

RAMIRES, C.H.; BERGER, E.L.; ALMEIDA, R. Influência da Qualidade Microbiológica da Água Sobre a Qualidade do Leite. Archives of Veterinary Science, v.14, n.1, p.36-42, 2009. Disponível em: <https://revistas.ufpr.br/veterinary/article/view/12913/10719>

SANTOS JÚNIOR, N.L; PINTO NETO, A.; SKONIESKI, F.; MOTA, M. F.; MARTINEZ, A. C. et al. Productive and reproductive profile of dairy farms from Realeza, Parana, Brazil. Livestock Research for Rural Development, v.28, n.9, p.1-6, 2016. Disponível em: <http://www.Irrd.org//rrd28/9/sant28165.html>

WERNCKE, D.; GABBI, A.M.; ABREU, A.S.; FELIPUS, N.C.; MACHADO, N.L. et al. Qualidade do leite e perfil das propriedades leiteiras no sul de Santa Catarina: abordagem multivariada. Arquivo Brasileiro de Medicina Veterinária e Zootecnia, v.68, n.2, p.506-516, 2016. Disponível em: <http://dx.doi.org/10.1590/1678-41628396> 
WINCK, C.A.; THALER NETO, A. Perfil de propriedades leiteiras de Santa Catarina em relação à Instrução Normativa 51. Revista Brasileira de Saúde e Produção Animal, Salvador, v.13, n.2, p.296-305, 2012. Disponível em: <http://www.scielo.br/pdf/rbspa/v13n2/a01v13n2.pdf>

ZANIN, A.; OENNING, V.; TRES, N.; KRUGER, S. D.; GUBIANI, C. A. Gestão das propriedades rurais do oeste de Santa Catarina: as fragilidades da estrutura organizacional e a necessidade do uso de controles contábeis. Revista Catarinense de Ciências Contábeis, v. 13, n. 40, 2014. Disponível em: <http://revista.crcsc.org.br/index.php/CRCSC/article/view/1885/1824> DOI: http://dx.doi.org/10.16930/2237-7662/rccc.v13n40p9-19 